\title{
Carbon Monoxide-Releasing Molecule-401 Suppresses Polymorphonuclear Leukocyte Migratory Potential by Modulating F-Actin Dynamics
}

\author{
Ken Inoue, ${ }^{*}$ Eric K. Patterson, ${ }^{*}$ Alfredo Capretta, ${ }^{\dagger}$ Abdel R. Lawendy, ${ }^{* \ddagger}$ Douglas D. Fraser, ${ }^{\star \S}$ and Gediminas Cepinskas ${ }^{* \ddagger}$
}

From the Centre for Critical Illness Research, ${ }^{*}$ Lawson Health Research Institute, London, Ontario; the Department of Chemistry, ${ }^{\dagger}$ McMaster University, Hamilton, Ontario; and the Departments of Medical Biophysics ${ }^{\ddagger}$ and Paediatrics, ${ }^{\S}$ University of Western Ontario, London, Ontario, Canada

\author{
Accepted for publication \\ December 27, 2016. \\ Address correspondence to \\ Gediminas Cepinskas, \\ D.V.M./Ph.D., Centre for \\ Critical Illness Research, \\ Lawson Health Research \\ Institute, 800 Commissioners \\ Rd E, VRL, A6-105A, \\ London, ON, Canada \\ N6C 6B5. E-mail: gcepinsk@ \\ uwo.ca.
}

\begin{abstract}
Carbon monoxide-releasing molecules (CORMs) suppress inflammation by reducing polymorphonuclear leukocyte (PMN) recruitment to the affected organs. We investigated modulation of PMN-endothelial cell adhesive interactions by water-soluble CORM-401 using an experimental model of endotoxemia in vitro. Human umbilical vein endothelial cells (HUVEC) grown on laminar-flow perfusion channels were stimulated with $1 \mu \mathrm{g} / \mathrm{mL}$ lipopolysaccharide for 6 hours and perfused with $100 \mu \mathrm{mol} / \mathrm{L}$ CORM-401 (or inactive compound iCORM-401)-pretreated PMN for 5 minutes in the presence of $1.0 \mathrm{dyn} / \mathrm{cm}^{2}$ shear stress. HUVEC:PMN co-cultures were perfused for additional 15 minutes with PMN-free medium containing CORM401/inactive CORM-401. The experiments were videorecorded (phase-contrast microscopy), and PMN adhesion/migration were assessed off-line. In parallel, CORM-401-dependent modulation of PMN chemotaxis, F-actin expression/distribution, and actin-regulating pathways [eg, p21-activated protein kinases (PAK1/2) and extracellular signal-regulated kinase (ERK)/C-Jun N-terminal kinase (JNK) mitogen-activated protein kinases (MAPK)] were assessed in response to $\mathrm{N}$-formyl-methionyl-leucylphenylalanine (FMLP) stimulation. Pretreating PMN with CORM-401 did not suppress PMN adhesion to HUVEC, but significantly reduced PMN transendothelial migration $(P<0.0001)$ and FMLP-induced PMN chemotaxis (ie, migration directionality and velocity). These changes were associated with CORM-401dependent suppression of F-actin levels/cellular distribution and FMLP-induced phosphorylation of PAK1/ 2 and ERK/JNK MAPK $(P<0.05)$. CORM-401 had no effect on $\mathrm{p} 38$ MAPK activation. In summary, this study demonstrates, for the first time, CORM-401-dependent suppression of neutrophil migratory potential associated with modulation of PAK1/2 and ERK/JNK MAPK signaling and F-actin dynamics. (Am J Pathol 2017, 187: 1121-1133; http://dx.doi.org/10.1016/j.ajpath.2016.12.025)
\end{abstract}

Sepsis, a syndrome of pathological abnormalities induced by infection, is a leading cause of deaths in intensive care units, with estimated mortality rates of $10 \%$ to $45 \% .^{1,2} \mathrm{An}$ initiating event in sepsis is generally, but not exclusively, attributed to the release of endotoxin [lipopolysaccharide (LPS)] from bacteria. ${ }^{3-5}$ It is well-known that LPS induces systemic activation of vascular endothelial cells and circulating polymorphonuclear leukocytes (PMNs), resulting in production of the proinflammatory mediators (eg, tumor necrosis factor- $\alpha$, IL-1 $\beta$, and reactive oxygen species)]. ${ }^{6-8}$ This scenario subjects vascular endothelial cells to potentially critical paracellular effects of adherent/migrating
PMN, which generate oxidative/proteolytic stress and subsequent vascular injury and dysfunction (eg, capillary leak).

PMN extravasation from the blood is controlled by wellcoordinated adhesive interactions between PMN and vascular endothelial cells, which involve rolling (P-, E-, L-selectins), firm adhesion ( $\beta 2$ integrins, intercellular adhesion molecule

\footnotetext{
Supported by Heart and Stroke Foundation (Ontario, Canada) research grant HSFO 393 (G.C.) and The Lawson Health Research Institute grant IRF 05-15 (G.C.).
}

Disclosures: None declared. 
1, vascular cell adhesion molecule 1), and migration across endothelium [platelet endothelial cell adhesion molecule 1 (PECAM-1), CD99, junctional adhesion molecules]. ${ }^{9,10}$ PECAM-1 (CD31), a tyrosine/serine phosphoprotein highly expressed on endothelial cells, platelets, and leukocytes, is considered to be the key molecule regulating PMN migration across the endothelial barrier. ${ }^{9,11-13}$

The migratory potential of PMN depends on rearrangement of the actin cytoskeleton to form a pseudopod (eg, lamellipodia and/or filopodia) toward the signal (eg, chemokine) and a trailing uropod in the posterior aspect of the cell. The pseudopod contains highly dynamic actin filaments that form an actin migratory cup. During migration, PMN extend the leading edge by local F-actin polymerization and contract the uropod by depolymerizing actin to allow movement in the direction of the signal. ${ }^{14}$

Rho-GTPases (eg, Cdc42, Rac, and Rho) play a crucial role in the establishment of inflammatory cell polarity that regulates localized actin polymerization and interaction with cell surface chemokine receptors and integrins. $^{14,15}$ p21-activated protein kinases (eg, PAK1/2) and MAP kinases [eg, p38/C-Jun N-terminal kinase (JNK)/ extracellular signal-regulated kinase (ERK)] are considered key targets of Rac GTPase signaling that controls actin dynamics in PMN. ${ }^{16,17}$

Regulation of PMN extravasation is important in achieving a balance between tissue protection and destruction. Overwhelming recruitment of PMN to the affected organs/tissues could amplify the inflammatory response and cause tissue injury. ${ }^{18}$ Given the acute nature and complexity of septic response(s), it is not surprising that there are no specific therapies to counteract excessive sepsis-associated systemic inflammation. ${ }^{6,19}$

Endogenously produced carbon monoxide (CO) (as a product of heme oxygenase activity) is recognized as a signaling molecule with potent anti-inflammatory effects. ${ }^{20-22}$ Recently, transitional metal carbonyls, CO-releasing molecules (CORMs), have been developed for delivery of $\mathrm{CO}$ in a controlled manner ${ }^{23,24}$ and demonstrated remarkable anti-inflammatory effects in various models. ${ }^{3,25-30}$ It has been demonstrated that CORM-derived $\mathrm{CO}$ offers anti-apoptotic, anti-atherosclerotic, and anti-inflammatory effects in animal models of ischemia-reperfusion, ${ }^{25,26}$ pulmonary hypertension, ${ }^{31}$ transplantation, ${ }^{27,32,33}$ compartment syndrome, ${ }^{28}$ and sepsis/endotoxemia. ${ }^{3,29,30}$ The protective effects of CORMs (eg, CORM-2 and CORM-3) can be attributed at least in part to their ability to modulate the PMN adhesive phenotype and interfere with PMN recruitment to the affected organs (eg, liver, lung, skeletal muscle). ${ }^{3,28,30,34}$ The mechanisms involved in CORM-dependent modulation of various steps of PMN recruitment (eg, adhesion and/or migration), however, remain largely unknown.

Herein, we hypothesized that CORM-401 (a new manganese-based and water-soluble CORM $)^{35}$ would modulate PMN adhesion/migration to/across vascular endothelial cells [human umbilical vein endothelial cells
(HUVECs)] in an experimental model of endotoxemia (LPS stimulation) and under experimental conditions of flow in vitro.

\section{Materials and Methods}

The study was approved by the Office of Research Ethics at Western University (London, ON, Canada).

\section{Reagents}

Carbon monoxide-releasing molecule-401 [CORM-401; $\mathrm{Mn}(\mathrm{CO})_{4}\left(\mathrm{~S}_{2} \mathrm{CNMeCH}_{2} \mathrm{CO}_{2} \mathrm{H}\right)$; molecular weight, 331.20] was synthesized by Dr. Alfredo Capretta (McMaster University, Hamilton, ON, Canada), as described in the previous report. ${ }^{35}$ Stock solutions of CORM-401 $(5 \mathrm{mmol} / \mathrm{L})$ were prepared in Hanks' balanced salt solution. Inactive CORM-401 (iCORM-401) was prepared by heating CORM-401 overnight at $60^{\circ} \mathrm{C}$ to liberate all $\mathrm{CO}$ from the molecule. M199 cell culture medium, fetal calf serum, penicillin, and streptomycin were purchased from Wisent (St-Bruno, QC, Canada). Endothelial cell mitogen was purchased from Biomedical Technologies (Stoughton, MA). Heparin was obtained from Pharmaceutical Partners of Canada (Richmond Hill, ON, Canada). Fibronectin and lipopolysaccharide (LPS; Escherichia coli serotype 055:B5) were purchased from Sigma-Aldrich (Oakville, ON, Canada).

The following antibodies were used in the study: mouse antihuman CD18 monoclonal antibody (clone TS1/18; Biolegend, San Diego, CA); mouse anti-human CD11a/CD18 monoclonal antibody (clone m24; Biolegend), goat anti-human vascular endothelial (VE)-cadherin polyclonal antibody (Santa Cruz Biotechnology Inc., Dallas, TX); rabbit anti-human PECAM-1 polyclonal antibody (Santa Cruz Biotechnology Inc.), antiphospho PAK1 $\left(\mathrm{Thr}^{423}\right) / \mathrm{PAK} 2\left(\mathrm{Thr}^{402}\right)$, and anti-PAK1/2 (Cell Signaling Technology, Beverly, MA). Anti-phospho ERK1 $\left(\mathrm{Thr}^{202} / \mathrm{Tyr}^{204}\right) / \mathrm{ERK} 2\left(\mathrm{Thr}^{185} / \mathrm{Tyr}^{187}\right)$ and anti-ERK1/ 2, anti-phospho JNK1/JNK2 $\left(\mathrm{Thr}^{183} / \mathrm{Tyr}^{185}\right)$ and JNK1/2, and anti-phospho p38 $\left(\mathrm{Thr}^{180} / \mathrm{Tyr}^{128}\right)$ and anti-p38 were purchased from Abcam Inc. (Cambridge, UK). Alexa Fluor 488 donkey anti-mouse $\operatorname{IgG}(\mathrm{H}+\mathrm{L})($ Abcam); Alexa Fluor 594 donkey anti-goat $\operatorname{IgG}(\mathrm{H}+\mathrm{L})$ (Life Technologies, Carlsbad, CA); Alexa Fluor 488 donkey anti-rabbit Ig G $(\mathrm{H}+\mathrm{L})$ (Life Technologies, Carlsbad, CA); Alexa Fluor 488-labeled phalloidin (Invitrogen, Waltham, MA); horseradish peroxidase-conjugated goat anti-rabbit antibody (Invitrogen) and horseradish peroxidase-conjugated anti-mouse antibody (Sigma-Aldrich).

\section{Endothelial Cell Culture}

HUVECs were harvested from human umbilical cord veins by collagenase treatment (Worthington Biochem, Freehold, $\mathrm{NJ}$ ), as previously described by us. ${ }^{10}$ HUVECs were cultured on fibronectin $(5 \mu \mathrm{g} / \mathrm{mL})$-coated cell culture dishes in M199 supplemented with $80 \mu \mathrm{g} / \mathrm{mL}$ endothelial cell 
mitogen, $10 \mathrm{U} / \mathrm{mL}$ heparin (Pharmaceutical Partners of Canada), $100 \mathrm{U} / \mathrm{mL}$ penicillin, $100 \mu \mathrm{g} / \mathrm{mL}$ streptomycin, and $10 \%$ fetal calf serum. For the experiments, passage 3 to 5 HUVECs were used.

\section{Polymorphonuclear Leukocytes}

Human PMNs were freshly isolated from venous blood of healthy volunteers using standard dextran sedimentation and gradient separation on Histopaque-1077 (Sigma-Aldrich). ${ }^{36}$ This procedure yields a PMN population that is $95 \%$ to 98\% viable (Trypan blue exclusion) and 98\% pure (acetic acid-crystal violet staining). Isolated PMNs were resuspended in phosphate-buffered saline (PBS) and kept on ice. Before any treatment, PMNs were incubated at room temperature for 10 minutes.

\section{Pretreatment of PMNs with CORM-401/iCORM-401}

Freshly isolated PMNs $\left(3 \times 10^{6}\right.$ cells $\left./ \mathrm{mL}\right)$ were resuspended in PBS containing $100 \mu \mathrm{mol} / \mathrm{L}$ CORM-401 or iCORM-401 for 30 minutes at room temperature. Subsequently, PMNs were used in various experiments.

\section{PMN-Endothelial Cell Adhesive Interaction under Flow Conditions}

HUVECs were grown on fibronectin $(5 \mu \mathrm{g} / \mathrm{mL})$-coated parallel flow perfusion slides ( $\mu$-Slide $\mathrm{IV}^{0.4}$; ibidi, Martinsried, Germany) for 48 hours. Confluent HUVEC monolayers were stimulated with $1 \mu \mathrm{g} / \mathrm{mL}$ LPS for 6 hours and transferred onto an inverted microscope (Diaphot 300; Nikon, Tokyo, Japan) equipped with an air-heated $\left(37^{\circ} \mathrm{C}\right)$ chamber. At that stage, the inlets of the slide channels were connected to a 5-mL syringe containing M199 cell culture medium and the outlets were connected to a syringe pump (Harvard Apparatus 22) set to withdrawing mode. HUVEC monolayers were first perfused with M199 for 5 minutes (washing step) and subsequently perfused with naïve- or CORM-401/iCORM-401-pretreated PMN $\left(1 \times 10^{6} / \mathrm{mL}\right)$ for 5 minutes in the presence of $1 \mathrm{dyn} / \mathrm{cm}^{2}$ shear stress. PMNs in the syringe reservoir were resuspended every 1 minute by gentle pipetting. After PMN perfusion over HUVEC monolayers for 5 minutes, the channels with PMN:HUVEC co-culture were connected to a continuous perfusion syringe pump (ibidi pump system 1.4; ibidi) and the HUVEC:PMN co-culture was perfused at $1 \mathrm{dyn} / \mathrm{cm}^{2}$ shear stress with PMN-free M199 medium containing $100 \mu \mathrm{mol} / \mathrm{L}$ CORM-401 or iCORM-401 for an additional 15 minutes. The whole experiment (one view field per channel; $\times 100$ magnification) was videorecorded (20 minutes total time) using a microscope-mounted video camera (CCD-IRIS; SONY, Tokyo, Japan), and the PMN:HUVEC adhesive interactions in $0.2 \mathrm{~mm}^{2}$ area were analyzed off-line. The number of PMNs in a $0.2-\mathrm{mm}^{2}$ area after the initial PMN perfusion for 5 minutes was considered as $100 \%$ adhesion. Arrested (ie, unmoving for at least 30 seconds), round, and under phase contrast microscopy bright white appearing PMNs were considered as adherent PMNs, whereas migrating PMNs were distinguished by their phase-dark morphology, as described previously. ${ }^{37}$

\section{Confocal Microscopy}

HUVEC-PMN interaction is described above. HUVECs:PMNs were fixed in 2\% paraformaldehyde in PBS for 15 minutes and prepared for immunofluorescence analysis, as previously described. ${ }^{10}$ Briefly, fixed HUVEC:PMN co-cultures were permeabilized for 15 minutes with $0.1 \%$ Triton-X and incubated for 1 hour at room temperature with primary mouse anti-human CD18 monoclonal antibody (1:400 dilution), followed by incubation with the secondary Alexa Fluor 488 donkey anti-mouse IgG (1:250 dilution) for an additional 1 hour. Subsequently, the samples were washed with PBS and incubated with primary goat anti-human VE-cadherin polyclonal antibody (1:400 dilution; 1 hour) and secondary Alexa Fluor 594 donkey anti-goat IgG (1:250 dilution; 1 hour) at room temperature, respectively. All antibodies were diluted in PBS containing $1 \%$ bovine serum albumin (BSA). Between procedures, the samples were washed $5 \times$ with PBS. Cell nuclei were labeled with $10 \mathrm{nmol} / \mathrm{L}$ Hoechst 33342 (Sigma-Aldrich) in PBS. Samples were mounted in ibidi-Mounting Medium (ibidi) and analyzed by Olympus Fluo View FV1000 coupled to the IX81 Motorized Inverted System confocal microscope (Olympus, Tokyo, Japan). Serial optical sections of samples were taken in the $\mathrm{z}$ direction using FV 10-ASW Fluo View 1000 software version 1.6 (Olympus).

PMN interaction with endothelial cells in the perfusion channels was quantified by counting PMNs in three consecutive areas $\left(0.2 \mathrm{~mm}^{2}\right.$ each) along the direction of perfusion. PMN morphological appearance was used as a marker for determining adherent versus migrating PMNs. Percentage round (adherent) and flattened (migrating) PMNs was determined in the $\mathrm{z}$ images of the same samples. On average, 25 to $30 \mathrm{PMNs}$ per $0.2 \mathrm{~mm}^{2}$ area were analyzed.

\section{PMN Chemotaxis and Morphometric Analysis}

CORM-401/iCORM-401-pretreated PMNs $\left(3 \times 10^{6}\right.$ cells/ $\mathrm{mL}$ ) were resuspended in Hanks' balanced salt solution $+0.1 \%$ BSA buffer containing $100 \mu \mathrm{mol} / \mathrm{L}$ CORM-401/iCORM-401 and placed into the $\mu$-Slide chemotaxis chamber (ibidi), according to the manufacturer's instructions. Briefly, PMNs were first placed into the chemotaxis chamber channels for 10 minutes at room temperature. Subsequently, $10 \mu \mathrm{mol} / \mathrm{L}$ $\mathrm{N}$-formyl-methionyl-leucyl-phenylalanine (fMLP) was added to the chemotaxis reservoir and the chemotaxis chamber was transferred to an inverted microscope (Diaphot 300; Nikon) equipped with an air-heated $\left(37^{\circ} \mathrm{C}\right)$ hood for 30 minutes to establish the fMLP diffusion gradient. After that, PMN movement was recorded every other minute for 20 minutes using a microscope-mounted video camera (CCD-IRIS; SONY). Five independent experiments were performed with 
20 to 45 cells analyzed in each experiment. Cell movement pattern, mean velocity, and y-forward migration index (ie, migration directionality) were analyzed with the Chemotaxis and Migration Tool plug-in [ImageJ software version 1.48 (NIH, Bethesda, MD; http://imagej.nih.gov/ij)]. ${ }^{38}$ In parallel, the morphological changes (eg, overall PMN length, width of PMN "tail," and width of PMN "head") occurring during the last 10 minutes of PMN chemotaxis were analyzed off-line using ImageJ software version 1.48.

\section{Analysis of F-Actin}

CORM-401/iCORM-401-pretreated PMNs $\left(1 \times 10^{7}\right.$ cells $\left./ \mathrm{mL}\right)$ were resuspended (final PMN concentration, $3 \times 10^{6}$ cells $/ \mathrm{mL}$ ) in Hanks' balanced salt solution $+0.1 \%$ BSA buffer for 10 minutes at $37^{\circ} \mathrm{C}$. Subsequently, PMNs were stimulated with $0.05 \mu \mathrm{mol} / \mathrm{L}$ fMLP for an additional 10 minutes at $37^{\circ} \mathrm{C}$, fixed with $2 \%$ paraformaldehyde (10 minutes at room temperature), permeabilized for 10 minutes in PBS containing $0.05 \%$ Triton X-100, blocked with 5\% BSA, and incubated with Alexa Fluor 488-phalloidin (1:40 dilution) for 30 minutes at room temperature in the dark.

Flow cytometry analysis was performed using Guava EasyCyte HT Flow Cytometer (EMD Millipore, Billerica, MA) and GuavaSoft software version 3.0 for data acquisition. Five thousand events were collected per sample. Mean fluorescence intensities were determined using GuavaSoft 3.0.

In parallel, CORM-401/iCORM-401-pretreated PMNs were stimulated with $0.05 \mu \mathrm{mol} / \mathrm{L}$ fMLP added into $\mu$-Slide $\mathrm{IV}^{0.4}$ (ibidi) perfusion channels and incubated for $10 \mathrm{mi}-$ nutes at $37^{\circ} \mathrm{C}$. F-actin staining (Alexa Fluor 488-phalloidin; 1:40 dilution) was performed as described above and analyzed by fluorescence microscopy (Zeiss Axiovert 200M; Carl Zeiss, Oberkochen, Germany).

\section{Expression of PECAM-1 (CD31) and $\beta_{2}$-Integrin (CD18)}

CORM-401/iCORM-401-pretreated PMNs were resuspended in PBS $\left(10 \times 10^{6}\right.$ cells $\left./ \mathrm{mL}\right)$ for 10 minutes at $37^{\circ} \mathrm{C}$, fixed with $2 \%$ paraformaldehyde in PBS for 10 minutes, and blocked with $5 \%$ BSA in PBS for 15 minutes at room temperature. The samples were then incubated for 30 minutes at room temperature with one of the following primary antibodies: anti-PECAM-1 (1:50 dilution), anti-CD18 (clone TS1/18; to detect the total levels of CD18; 1:200 dilution), or anti-CD11a/CD18 (clone $\mathrm{m} 24$; to assess activation of $\beta_{2}$-integrin; 1:200 dilution), followed by incubation with secondary Alexa Fluor 488 donkey anti-rabbit antibody (for PECAM-1) and Alexa Fluor 488 donkey anti-mouse antibody (for CD18, 1:4000 dilution; and CD11a/CD18, 1:2000 dilution) in PBS for 30 minutes at room temperature, respectively. All antibodies were prepared in PBS containing 1\% BSA. The levels of PECAM-1 (CD31) and $\beta_{2}$-integrin (CD18) expression were analyzed by flow cytometry (Guava EasyCyte HT Flow Cytometer; EMD Millipore). Mean fluorescence intensities were determined using GuavaSoft 3.0.

\section{Immunoblotting}

CORM-401/iCORM-401-pretreated PMNs $\left(3 \times 10^{7}\right.$ cells/ $100 \mu \mathrm{L}$ PBS) were incubated for 10 minutes at $37^{\circ} \mathrm{C}$, and stimulated with $0.05 \mu \mathrm{mol} / \mathrm{L}$ fMLP for 15 seconds. Subsequently, $50 \mu \mathrm{L}$ of cold $\left(4^{\circ} \mathrm{C}\right) 3 \times$ extraction buffer (final concentration: $50 \mathrm{mmol} / \mathrm{L}$ Tris, $\mathrm{pH} 7.5,10 \mathrm{mmol} / \mathrm{L} \mathrm{MgCl}_{2}$, $0.5 \mathrm{~mol} / \mathrm{L} \mathrm{NaCl}, 2 \%$ Igepal, $0.4 \mathrm{mmol} / \mathrm{L} \mathrm{Na}_{3} \mathrm{VO}_{4}$, protease inhibitor and phosphatase inhibitor) was added to the cells for 2 minutes. Then, the samples were centrifuged $(10,000 \times g)$ at $4^{\circ} \mathrm{C}$ for 15 minutes, supernatants collected, and subjected to SDS-PAGE (8\%). Protein concentration was determined by MicroBCA assay (BioRad, Mississauga, ON, Canada). Proteins were transferred overnight to a BioTrace polyvinylidene difluoride membrane (Pall Corp., Port Washington, NY) followed by membrane blocking with 2\% BSA in PBS for 1 hour at room temperature with constant agitation. The membranes were probed with the anti-phospho PAK1 $\left(\mathrm{Thr}^{423}\right) /$ PAK2 $\left(\mathrm{Thr}^{402}\right.$ ) antibody diluted in 5\% BSA/0.1\% Tween in Tris-buffered saline at $4^{\circ} \mathrm{C}$ overnight, followed by incubation with the secondary horseradish peroxidase-conjugated goat anti-rabbit antibody for 1 hour. In parallel, the membranes were incubated with anti-phospho Erk1/2 [ERK1 $\left(\mathrm{Thr}^{202} / \mathrm{Tyr}^{204}\right) /$ ERK2 $\left.\left(\mathrm{Thr}^{185} / \mathrm{Tyr}^{187}\right)\right]$, anti-phospho JNK1/2 [JNK1/JNK2 $\left(\mathrm{Thr}^{183} / \mathrm{Tyr}^{185}\right)$ ], or anti-phospho $\mathrm{p} 38\left(\mathrm{Thr}^{180} / \mathrm{Tyr}^{128}\right)$ antibody diluted in $2 \%$ nonfat-dry milk in Tris-buffered saline at room temperature for 1 hour. The membranes were then washed and incubated with secondary horseradish peroxidase-conjugated anti-rabbit or anti-mouse antibody. Target antibodies were detected using enhanced chemiluminescence detection (2.5 $\mathrm{mmol} / \mathrm{L}$ Luminol, $0.4 \mathrm{mmol} / \mathrm{L}$ p-Coumaric acid, $0.02 \%$ hydrogen peroxide in $100 \mathrm{mmol} / \mathrm{L}$ Tris buffer; Sigma-Aldrich). Images of the immunoblots were captured using the MicroChemi Bio-imaging system (DNR, Jerusalem, Israel) and band was quantified with GelQuant Pro software version 11.5 (Froggabio, Toronto, ON, Canada).

The same membranes were reprobed with anti-PAK1/2, anti-ERK1/2, anti-JNK1/2, and anti-p38 antibody after membrane stripping with $2 \%$ SDS $/ 0.78 \% \beta$-mercaptoethanol buffer. Levels of protein phosphorylation were normalized to the total levels of the respective proteins.

\section{Cell Viability}

PMN viability was assessed using Guava ViaCount Flex Reagent (EMD Millipore) in accordance to the manufacturer's instruction. Briefly, freshly isolated PMNs $\left(0.5 \times 10^{6}\right.$ cells $\left./ \mathrm{mL}\right)$ were suspended in PBS containing 50, 100 , or $200 \mu \mathrm{mol} / \mathrm{L}$ of CORM-401/iCORM-401 and incubated at $37^{\circ} \mathrm{C}$ for 30,60 , or 90 minutes. At the indicated time points, cell viability was assessed using flow cytometry (Guava EasyCyte 12HT; EMD Millipore).

\section{Statistical Analysis}

Statistical analyses were performed with GraphPad Prism software version 5 (GraphPad Software, San Diego, CA) 
A

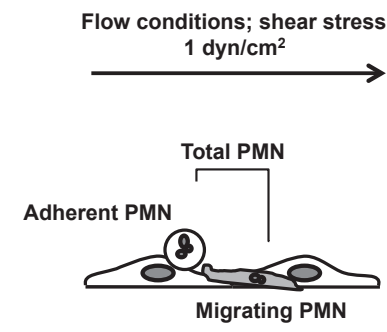

B

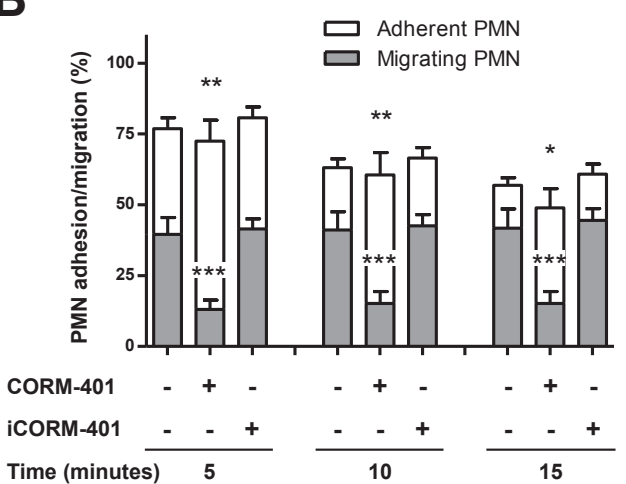

Figure 1 Pretreatment of polymorphonuclear leukocytes (PMNs) with CORM-401 suppresses PMN migration across human umbilical vein endothelial cells (HUVECS) under conditions of flow. A: Schematic depicting adherent and migrating PMNs under experimental conditions of flow in vitro. B: HUVECs were grown on perfusion slides and stimulated with $1 \mu \mathrm{g} / \mathrm{mL}$ LPS for 6 hours. Subsequently, HUVECs were interacted with naïve, CORM-401, or iCORM-401 $(100 \mu \mathrm{mol} / \mathrm{L} ; 30$ minutes $)$ pretreated PMNs $\left(1 \times 10^{6} / \mathrm{mL}\right)$ for 5 minutes in the presence of $1 \mathrm{dyn} / \mathrm{cm}^{2}$ shear stress. Next, the HUVEC-PMN co-culture was perfused with PMN-free medium containing CORM-401 or iCORM-401 for additional 15 minutes. The experiment was videorecorded using phasecontrast microscopy and adherent and migrating PMNs were counted in a $0.2-\mathrm{mm}^{2}$ area. $n=5$ in duplicate (B). ${ }^{*} P<0.05,{ }^{*} P P<0.01$, and $* * * P<0.001$ as compared to untreated and iCORM-401-treated groups within adherent PMN and migrating PMN categories, respectively.

on a Windows-based computer. Data are presented as means \pm SEM for the indicated number of separate experiments. Differences between groups were determined by analysis of unpaired $t$-test, analysis of variance, and a Bonferroni's multiple comparison test and/or a two-way repeated measure analysis of variance. $P<0.05$ was considered statistically significant.

\section{Results}

Our findings using phase-contrast/videomicroscopy indicate that PMNs effectively adhere to and migrate across LPSstimulated HUVECs in the presence of laminar flow (shear stress, $1 \mathrm{dyn} / \mathrm{cm}^{2}$ ) in vitro (Figure 1, A and B).

Further analysis of PMN-HUVEC adhesive interactions indicates that pretreatment of PMN with $100 \mu \mathrm{mol} / \mathrm{L}$ CORM-401 (but not iCORM-401) preferentially suppresses PMN migratory potential, while having no inhibitory effect on PMN adhesion per se as assessed at 5, 10, and 15 minutes time points after PMN-HUVEC interaction (Figure 1B).
Confocal microscopy analysis supports the above findings and indicates that PMNs in LPS- and LPS + iCORM401-treated groups flatten and localize primarily between/ underneath HUVECs, indicating expression of PMN promigratory phenotype (Figure 2, A and B). On the contrary, CORM-401-pretreated PMNs (LPS + CORM-401 group) mostly appear round in shape and despite firm adhesion, fail to flatten and migrate across HUVECs, suggesting suppression of PMN migratory potential (Figure 2, A and B). Further quantitative analysis of PMN morphological appearance using the confocal microscopy approach indicates that $69 \%$ of naïve and $71 \%$ of iCORM-401-pretreated PMNs appear flattened (ie, display promigratory phenotype), whereas only $19 \%$ of CORM-401-pretreated PMNs display similar phenotype. On the contrary, $>80 \%$ of PMNs in CORM-401-pretreated group appear round and thus, display the proadhesive but not promigratory phenotype (Figure 2C).

Experiments addressing potential modulation of PMN adhesive/migratory phenotypes by CORM-401 indicate that CORM-401 pretreatment does not affect the levels and activation of $\beta_{2}$-integrin (CD18), the main adhesion molecule involved in PMN recruitment to vascular endothelium. In this regard, the total cell surface levels of $\beta_{2}$-integrin and activation of $\beta_{2}$-integrin [as assessed by the levels of CD11a/CD18 ( $\alpha_{\mathrm{L}} \beta_{2}$ integrin; LFA-1) expression] were not affected by CORM-401/iCORM-401 pretreatment (Figure 3, A and B, respectively). In addition, CORM-401 had no effect on the surface expression levels of PECAM1 (CD31), the molecule primarily responsible for PMN migration across vascular endothelium (Figure 3C).

Interestingly, further experiments designed to address potential mechanism(s) of CORM-401-dependent modulation of PMN migratory potential indicate that CORM-401 interferes with the cytoskeletal (eg, F-actin) rearrangement in inflammatory stimulus (eg, fMLP)-challenged PMNs. Our findings indicate that pretreatment of PMNs with CORM-401 (but not iCORM-401) inhibits the fMLPinduced increase in total F-actin levels (Figure 4A) and interferes with the F-actin dynamics (eg, formation of F-actin migratory cups). In regard to the latter, CORM401-pretreated PMNs are unable to form a well-defined F-actin-rich leading edge (ie, migratory cup) evidenced by accumulation of F-actin at the migrating front (ie, pseudopod), and instead demonstrate punctate and irregular F-actin staining (resembling the one observed in unstimulated cells) throughout the periphery (Figure 4B).

PMN function (eg, migration)- and F-actin levels/ dynamics-modulating effects of CORM-401 are associated with intracellular accumulation of CO in CORM-401(but not iCORM-401)-pretreated PMNs (Supplemental Figure S1). Under experimental conditions used in this study, CORM-401 effectively releases CO (Supplemental Figure S1A) that can be detected in PMNs by cell membrane-permeable CO-specific fluorochrome, COP- $1^{39}$ (Supplemental Figure S1B). 
A

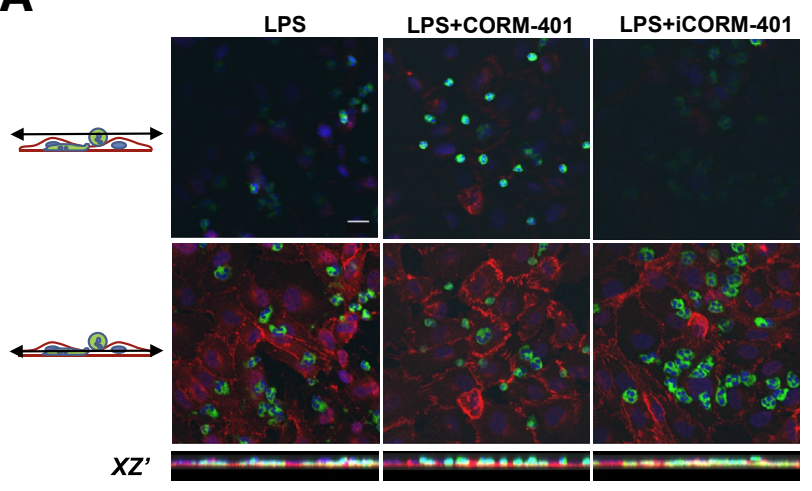

C

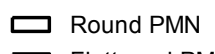

$\square$ Flattened PMN

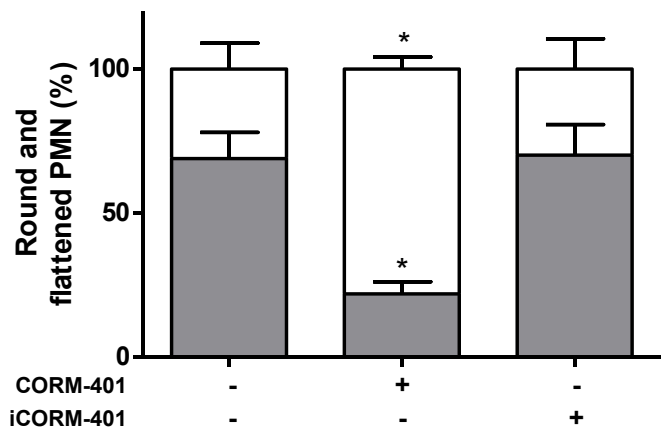

Further experiments addressing CORM-401-dependent modulation of PMN migration indicate that pretreatment of PMNs with CORM-401 changes fMLP-induced PMN chemotaxis pattern, as assessed by real-time video analysis of PMN migration in chemotactic chambers (Figure 5A). It appears that CORM-401 pretreatment not only interferes with PMN migration directionality but also effectively suppresses PMN migration velocity in response to fMLPinduced chemotaxis (Figure 5, B and C, respectively; and Supplemental Videos S1-S3). Interestingly, impaired PMN migration directionality and reduced migration velocity were accompanied by CORM-401 (but not iCORM-401)-dependent induction of morphological changes observed during fMLP-induced PMN migration (Supplemental Videos S1-S3). Morphometric analysis (Figure 6D) of the migrating PMN indicates that during fMLP-induced migration, CORM-401-pretreated PMNs appear elongated (Figure 6A) and possess narrow cytoplasmic tails (ie, uropods) (Figure 6B) as compared to fMLP-only or fMLP + iCORM-401-treated PMNs. The width of the PMN "head," however, remained unchanged

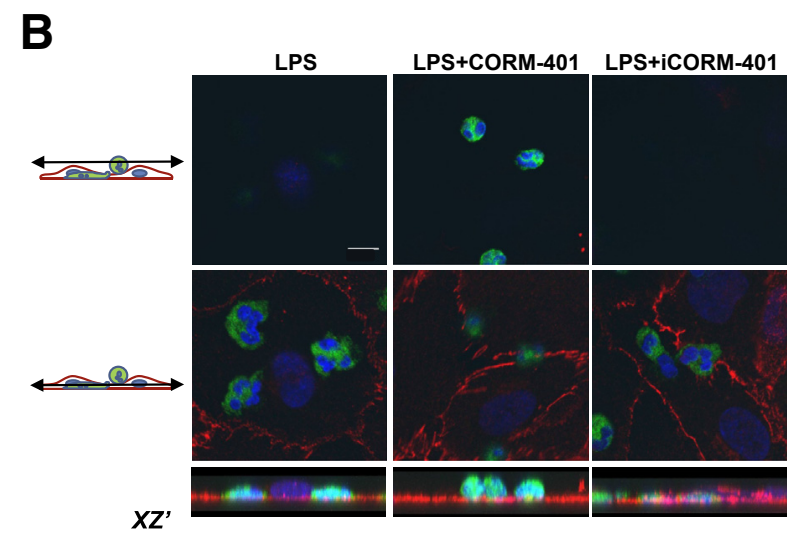

Figure 2 Confocal microscopy analysis of human umbilical vein endothelial cell (HUVEC)-polymorphonuclear leukocyte (PMN) adhesive interaction after pretreatment of PMNs with CORM-401. HUVECs were grown on perfusion slides and stimulated with $1 \mu \mathrm{g} / \mathrm{mL}$ LPS for 6 hours. Next, HUVECs were interacted with naïve, CORM-401, or iCORM-401 $(100 \mu \mathrm{mol} / \mathrm{L})$ pretreated PMNs $\left(1 \times 10^{6}\right)$ $\mathrm{mL}$ ) for 5 minutes in the presence of $1 \mathrm{dyn} / \mathrm{cm}^{2}$ shear stress. Subsequently, the HUVEC-PMN co-culture was perfused with PMN-free medium containing 100 $\mu \mathrm{mol} / \mathrm{L}$ CORM-401 or iCORM-401 for an additional 5 minutes. At that point, PMN-HUVEC co-cultures were fixed with $3 \%$ paraformaldehyde and immunostained for VE-cadherin (marker of endothelial cells; red fluorescence) and $\beta_{2^{-}}$ integrin (CD18) (marker of leukocytes; green fluorescence). Cell nuclei were stained with Hoechst 33342 (blue fluorescence). PMN-HUVEC co-culture at low (A) and high (B) magnification. The focal planes of the images are indicated in the adjacent diagrams. Representative images from three independent experiments are shown. C: Quantitative analysis of adherent versus migrating PMNs is presented. PMNs were quantified in three consecutive areas $\left(0.2 \mathrm{~mm}^{2}\right.$ each) for morphological appearance. Percentage of round (adherent) versus flattened (migrating) PMNs was calculated in the $z$ images of the same samples. $n=3$ (C). ${ }^{*} P<0.05$ as compared to untreated and iCORM-401-treated groups. Scale bars: $20 \mu \mathrm{m}(\mathbf{A}) ; 10 \mu \mathrm{m}($ B). Original magnifications: $\times 200($ A) $; \times 600$ (B).

(Figure 6C). Pretreatment of PMNs with CORM-401 or iCORM-401 at various concentrations (5 to 200 $\mu \mathrm{mol} / \mathrm{L}$ ) had no effect on PMN viability (Supplemental Figure S2).

Actin cytoskeletal reorganization and subsequent cell motility/migration is tightly controlled by Rho-GTP and Cdc42/Rac1-GTP signaling pathways with PAK1/2 kinase being one of the key end-target effector molecules in Cdc42/ Rac1-GTP signaling. ${ }^{16,17,40}$ Our findings with respect to the above indicate that pretreatment of PMNs with CORM-401 effectively suppresses fMLP-induced activation of PAK1/2 as assessed by the levels of PAK1/PAK2 phosphorylation (Figure 7). In parallel, CORM-401 was effective in reducing fMLP-induced activation (ie, increased phosphorylation) of the MAP kinases, Erk1/2, and JNK1/2 (Figure 8, A, C, and $\mathrm{E}$ and $\mathrm{B}, \mathrm{D}$, and F, respectively). Despite some moderate decrease in p38 mitogen-activated protein kinase (MAPK) phosphorylation observed in CORM-401-pretreated PMNs, the overall levels of fMLP-induced p38 MAPK phosphorylation were not significantly affected by CORM401 (Figure 8, G and H). 

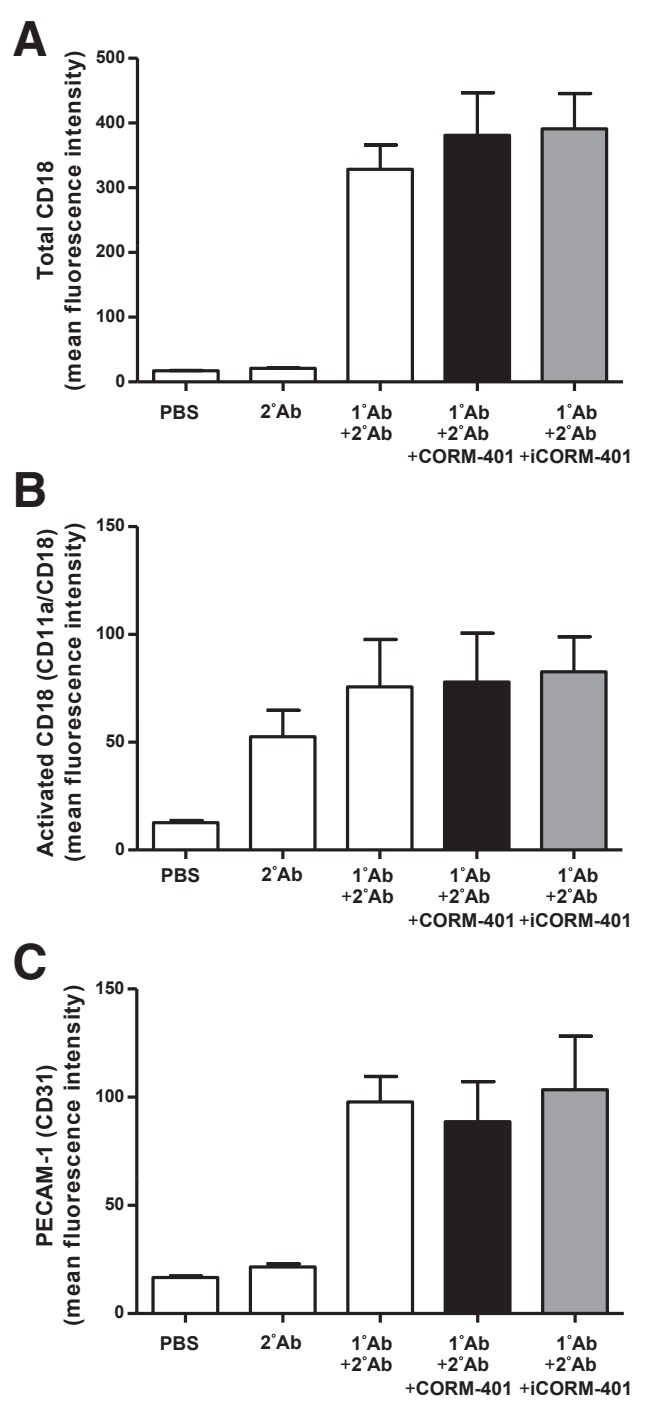

Figure 3 Surface levels and activation levels of $\beta_{2}$-integrin (CD18) and PECAM-1 (CD31) in CORM-401-pretreated polymorphonuclear leukocytes (PMNs). Naïve PMNs were pretreated with $100 \mu \mathrm{mol} / \mathrm{L}$ CORM-401 or iCORM401 for 30 minutes, fixed, and analyzed by flow cytometry for the total cell surface levels of $\mathrm{CD} 18$ (A) and activation of $\mathrm{CD} 18$ with respect to expression of CD11a/CD18 (B). C: In parallel, surface levels of PECAM-1 (CD31) were also assessed. Protein expression levels are expressed as mean fluorescence intensity. $n=5$. Ab, antibody; PBS, phosphatebuffered saline.

\section{Discussion}

In this study, we report that CORM-401, a manganese-based water-soluble CO-releasing molecule, ${ }^{35}$ interferes with PAK1/2 and MAPK (eg, ERK/JNK) signaling and F-actin levels/dynamics in PMNs. Ultimately, PMN migration across the vascular endothelial barrier is suppressed. This is the first study demonstrating that CORM-401 prevents or decreases the rate at which PMNs polarize, display promigratory phenotype, and migrate across vascular endothelial cell barrier.

$\mathrm{CO}$, a natural end product of heme oxygenase activity in mammalian tissues, exhibits potent anti-inflammatory effects. $^{20,24,41}$ The therapeutic use of CO (in a form of inhaled gas), however, is hampered by formation of toxic levels $(>15 \%)$ of carboxyhemoglobin. ${ }^{42-44}$ To overcome the latter limitation, transitional metal carbonyls, CO-releasing molecules (CORMs), have been developed for delivery of $\mathrm{CO}$ in a controlled manner, without significant effects on carboxyhemoglobin formation $(<3 \%$ to $5 \%$ carboxyhemoglobin). ${ }^{23,24,28,42}$ To date, several CORMs (eg, CORM-2, CORM-3, CORM-A1) possessing different chemical properties with respect to solubility, and the mechanism, rate, and amount of $\mathrm{CO}$ release, have been synthesized and assessed in various systems. ${ }^{24}$ Most recently, a water-soluble manganese-based CORM (CORM401) that releases $3 \mathrm{~mol} \mathrm{CO} / 1 \mathrm{~mol}$ CORM-401 ( $\mathrm{t}_{1 / 2} 20$ minutes) has been synthesized. ${ }^{35}$
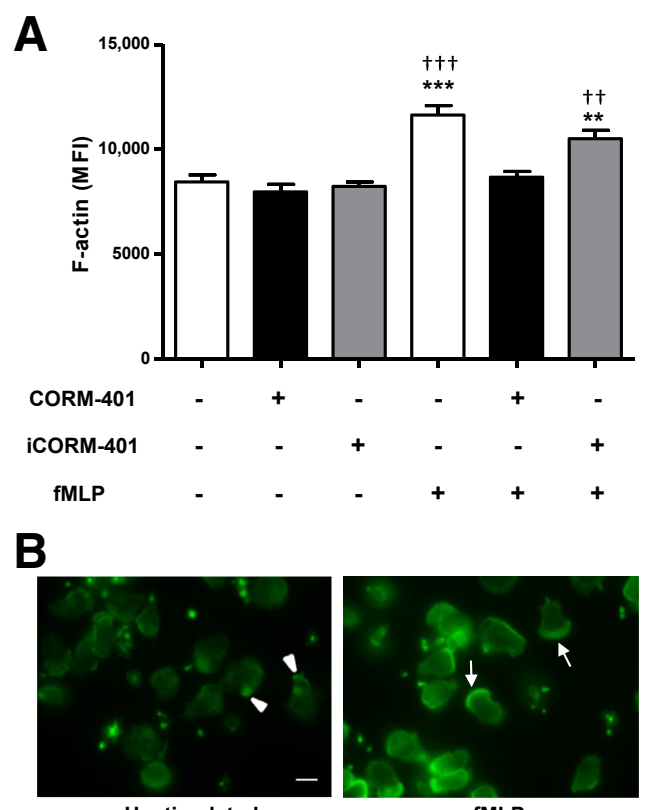

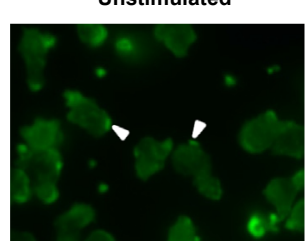

fMLP+CORM-401

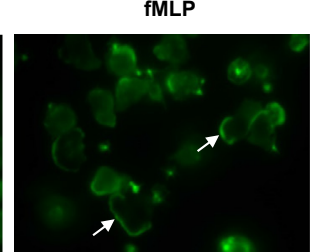

fMLP+iCORM-401
Figure 4 CORM-401 modulates F-actin levels and dynamics in FMLPstimulated polymorphonuclear leukocytes (PMNs). A: Naïve, CORM-401, or iCORM-401 (100 $\mu \mathrm{mol} / \mathrm{L} ; 30$ minutes) pretreated PMNs were challenged with $0.05 \mu \mathrm{mol} / \mathrm{L}$ fMLP for 10 minutes. Subsequently, F-actin levels (Alexa Fluor 488phalloidin staining) were quantified by flow cytometry and expressed as mean fluorescence intensity (MFI). B: CORM-401 or iCORM-401-pretreated PMNs were placed into perfusion channels and stimulated with $0.05 \mu \mathrm{mol} / \mathrm{L} \mathrm{fMLP}$ for 10 minutes. F-actin staining (Alexa Fluor 488-phalloidin) was visualized by fluorescence microscopy. Punctate cortical staining of F-actin and the absence of F-actin migratory cups are indicated by the arrowheads. The formation of $\mathrm{F}$-actin migratory cups is indicated by the arrows. Representative images from three independent experiments are shown. $n=5$ (in duplicate; $\mathbf{A}$ ). ${ }^{* *} P<0.01$, ${ }^{* * * P}<0.001$ compared to unstimulated cells; ${ }^{\dagger \dagger} P<0.01,{ }^{+\dagger \dagger} P<0.001$ compared to CORM-401 + fMLP stimulated cells. Scale bar: $10 \mu \mathrm{m}$ (B). 


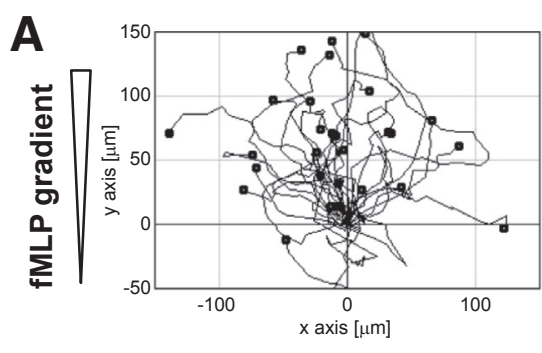

fMLP

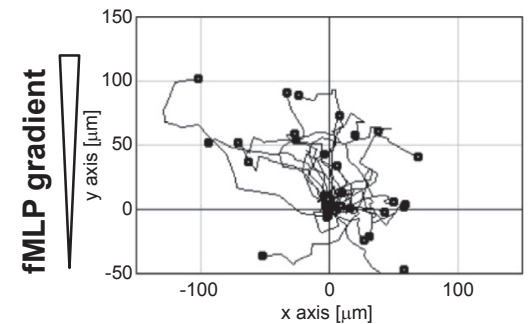

fMLP+CORM-401
B

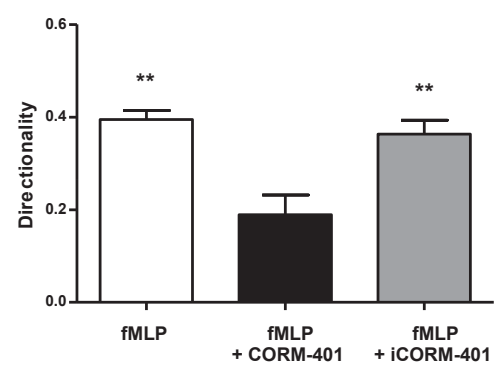

C

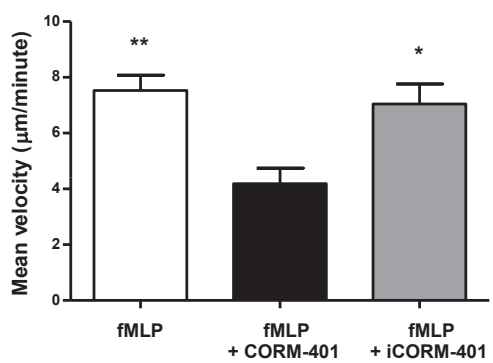

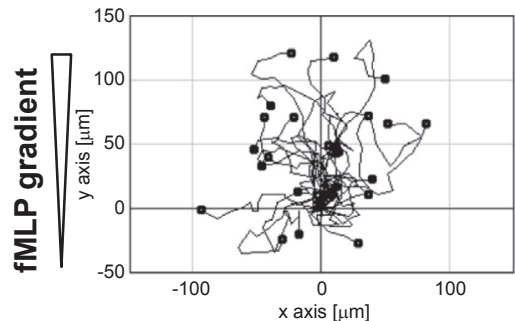

fMLP+iCORM-401

Figure 5 CORM-401 modulates polymorphonuclear leukocyte (PMN) migratory pattern during chemotaxis in vitro. Naïve, CORM-401, or iCORM-401 (100 $\mu \mathrm{mol} / \mathrm{L} ; 30$ minutes) pretreated PMNs were placed into the $\mu$-Slide chemotaxis chambers and exposed to an FMLP chemotactic gradient ( 0 to $10 \mu \mathrm{mol} / \mathrm{L}$ ) for 50 minutes. A: PMN migration was videorecorded and PMN migration tracks were generated using Chemotaxis and Migration Tool plug-in software (ImageJ version 1.48). Subsequently, PMN migration directionality ( $\mathrm{y}$-forward migration index; $\mathbf{B})$ and velocity $(\mu \mathrm{m} /$ minute; $\mathbf{C})$ were quantified off-line. $n=5$ (B and $\mathbf{C})$. ${ }^{*} P<0.05,{ }^{* *} P<0.01$ compared to fMLP + CORM-401 group.

The protective effects of exogenous $\mathrm{CO}$ are the subject of intense investigations. Despite some progress in the field, the mechanism(s) of CO-dependent modulation of inflammation remain poorly understood and often are controversial. The diverse effects/mechanisms of exogenously administered $\mathrm{CO}$ may be attributed at least in part to the differences in the rate of $\mathrm{CO}$ release from CORMs, actual $\mathrm{CO}$ concentrations that reach the biological target, temporal and spatial CO distribution, proximity of the heme/ metal-containing proteins, and even to the cell type investigated. ${ }^{22,30,45-47}$

Our findings indicate that CORM-401 used in this study effectively releases $\mathrm{CO}$ as evidenced by formation of carboxymyoglobin (Supplemental Figure S1A). Moreover, CORM-401 pretreatment induces intracellular accumulation of $\mathrm{CO}$ in PMNs, as evidenced by increased
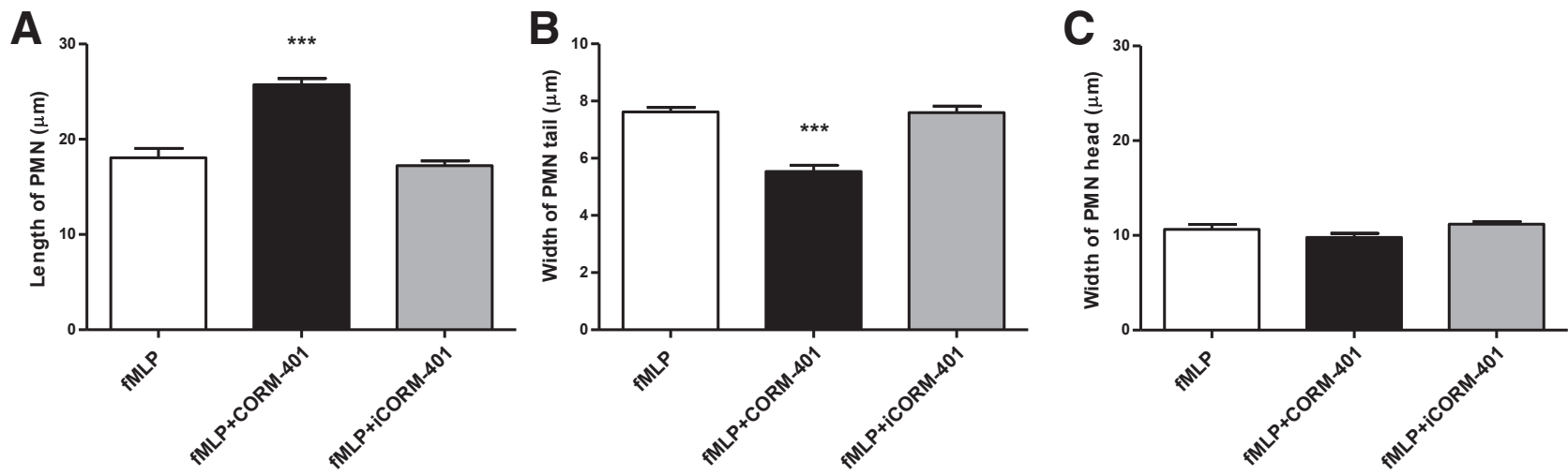

D

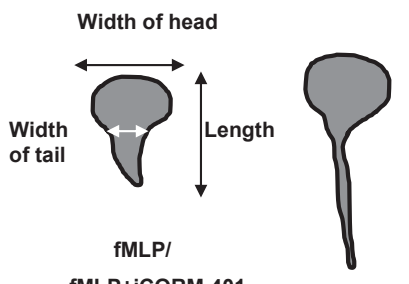

Figure 6 Morphometric changes in CORM-401-pretreated polymorphonuclear leukocytes (PMNs) during chemotaxis in vitro. Naïve, CORM-401, or iCORM-401 (100 $\mu \mathrm{mol} / \mathrm{L} ; 30$ minutes) pretreated PMNs were placed into the $\mu$-Slide chemotaxis chambers and exposed to an FMLP chemotactic gradient ( 0 to 10 $\mu \mathrm{mol} / \mathrm{L}$ ) for 50 minutes. PMN chemotaxis was videorecorded and PMN morphological changes with respect to overall PMN length $(\mathbf{A})$, width of PMN tail (B), and width of PMN head $(\mathbf{C})$ were analyzed at the 40-minute time point. D: Schematic representing PMN morphological changes and experimental measures. $n=5(\mathbf{A}-\mathbf{C}) .{ }^{* * *} P<0.001$ compared to fMLP and fMLP + iCORM-401 groups. 
A

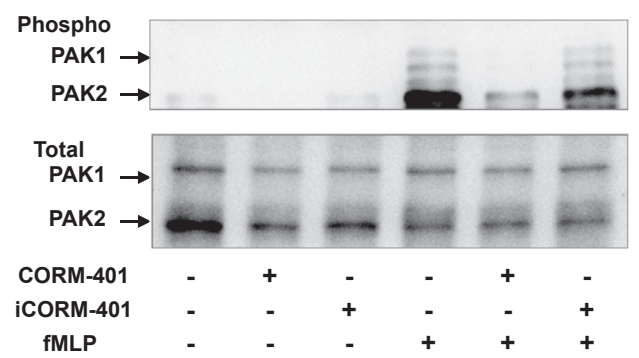

B
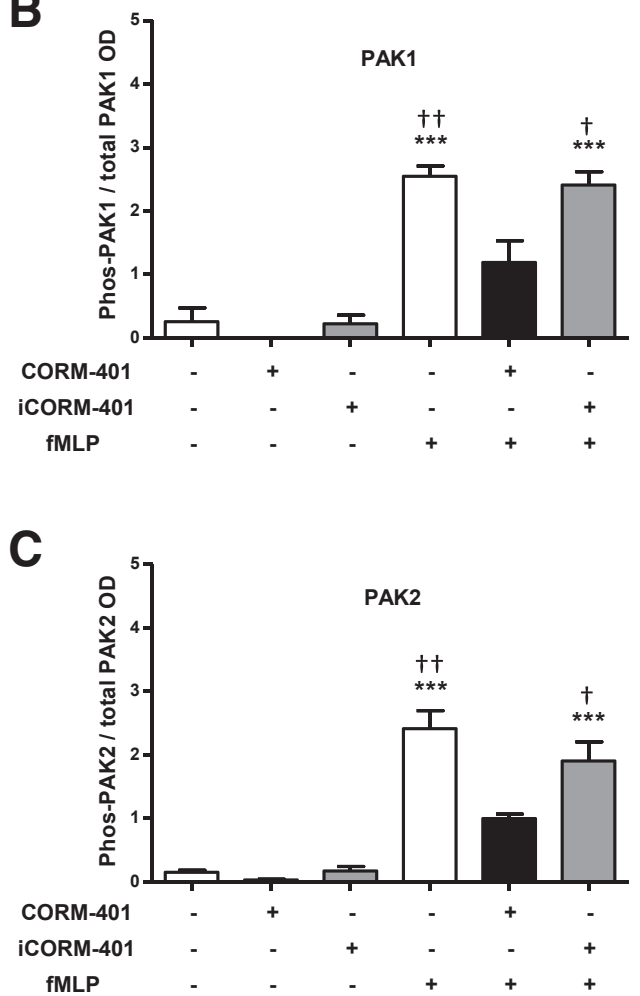

Figure 7 Pretreatment of polymorphonuclear leukocytes (PMNs) with CORM-401 suppresses FMLP-induced activation of PAK1/2. A: PMNs were pretreated with $100 \mu \mathrm{mol} / \mathrm{L}$ CORM-401 or iCORM-401 for 30 minutes and stimulated with $0.05 \mu \mathrm{mol} / \mathrm{L}$ fMLP for 15 seconds. Subsequently, PMNs were analyzed for PAK1/2 activation [PAK1 $\left(\mathrm{Thr}^{423}\right) /$ PAK2 $\left(\mathrm{Thr}^{402}\right)$ phosphorylation] and total PAK1/2 levels by Western blotting. Specific band intensities were quantified by densitometry (OD). B and C: Levels of PAK1 and PAK2 phosphorylation were standardized to the total levels of PAK1/2 protein expression, respectively. A: Representative blots from three independent experiments are shown. ${ }^{* * *} P<0.001$ compared to unstimulated cells; ${ }^{\dagger} P<0.05,{ }^{\dagger \dagger} P<0.01$ compared to CORM-401 + fMLP group. Phospho, phosphorylation.

fluorescence of cell membrane-permeable CO-specific fluorochrome, COP-1 ${ }^{39}$ (Supplemental Figure S1B). Furthermore, we demonstrate that pretreatment of PMNs with CORM-401 effectively interferes with PMN migration across LPS-stimulated HUVECs. PMN migrationsuppressing effects of CORM-401 were not associated with modulation of surface expression levels/activation of adhesion molecules, such as $\beta_{2}$-integrin (CD18) or PECAM-1 (CD31). These findings are in conflict with a previous study demonstrating that CORM-3 was effective in reducing $\mathrm{CD} 11 \mathrm{~b} / \mathrm{CD} 18$ ( $\beta_{2} \alpha_{\mathrm{M}}$ integrin) levels in platelet activating factor-stimulated PMNs, resulting in reduced PMN adhesion to tumor necrosis factor- $\alpha$ stimulated HUVECs under experimental conditions of flow. ${ }^{34}$ Interestingly, the same study demonstrated no effects of CORM-3 on PECAM-1 expression in tumor necrosis factor- $\alpha-$ stimulated endothelium. The exact nature of why CORM-401 did not affect surface levels of $\beta_{2}$-integrin and did not affect (ie, reduced) PMN adhesion per se to LPSstimulated HUVECs is unknown. However, it could be at least in part attributed to the differences in the following: i) duration and mode of PMN treatment with CORMs (eg, 10 minutes pretreatment with CORM-3 versus 30 minutes pretreatment with CORM-401), ii) amount and rate of CO release by CORMs (eg, $1 \mathrm{~mol} \mathrm{CO} / 1 \mathrm{~mol}$ CORM-3, $\mathrm{t}_{1 / 2} 1$ minute; and $3 \mathrm{~mol} \mathrm{CO} / 1 \mathrm{~mol}$ CORM-401, $\mathrm{t}_{1 / 2} 20$ minutes), and iii) stimulus used to activate PMNs (eg, platelet activating factor in the CORM-3 study versus LPS or fMLP in the current study using CORM-401).

PMN diapedesis is guided by the chemotactic molecules (eg, fMLP) produced by invading pathogens ${ }^{48}$ and/or chemokines produced by inflammatory cells, vascular endothelial, and interstitial cells of the host (eg, CXCL1-3, CXCL8). ${ }^{36,49}$ Inflammatory cell migration is driven by a rapid reorganization of the cytoskeleton, the process that is tightly controlled by Rho-GTPases. ${ }^{14,15}$

p21-Activated kinases (PAKs: PAK1, PAK2, and PAK3) constitute a family of serine/threonine kinases activated by Rac and Cdc42 and are down-stream effectors of RhoGTPase signaling that are implicated in inflammatory cell (eg, PMN and macrophage) activation (eg, $\mathrm{O}_{2}^{-}$generation) and migration. ${ }^{50}$ Activation of PAK involves phosphorylation of the thr423, thr402, and ser141 residues. ${ }^{50}$ PAKs are activated by chemoattractants, such as $\mathrm{fMLP},{ }^{40}$ and are implicated in PMN actin cytoskeletal rearrangement, directionality, and migration speed. ${ }^{51,52}$

The results of the current study indicate that CORM-401 effectively inhibits activation of PAK1/2 (eg, the levels of PAK1/2 phosphorylation) that was associated with reduced F-actin levels, impaired actin cytoskeletal remodeling, and subsequent suppression of PMN migration. In regard to the latter, previous findings indicate that specific PAK-inhibitory peptide not only suppresses PAK activation, but also reduces PMN accumulation in the lungs of LPS-challenged mice. ${ }^{17}$ Interestingly, the latter study also demonstrated that pretreatment of PMNs with the inhibitory PAK peptide reduced PMN accumulation in the lung interstitium and alveolar space (but not in the vascular space), suggesting that PAK preferentially regulates PMN migration. We observed a similar phenomenon; CORM-401-induced inhibition of PAK1/2 activation was associated with suppressed PMN migration across an LPS-stimulated vascular endothelial barrier. However, CORM-401 had no inhibitory effect on 
A

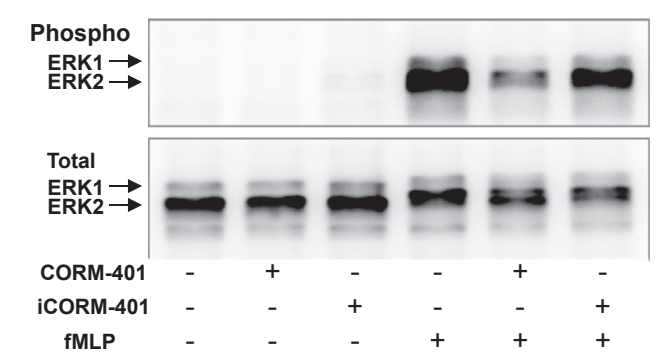

C

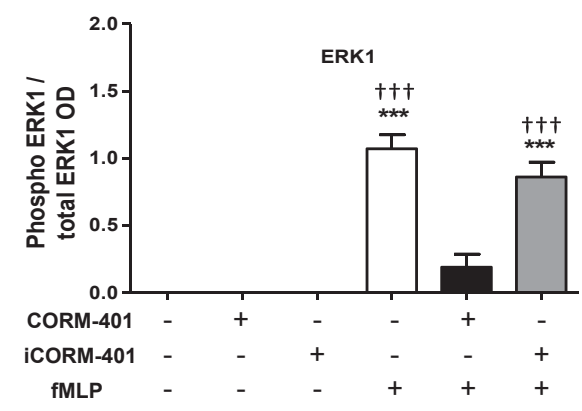

E

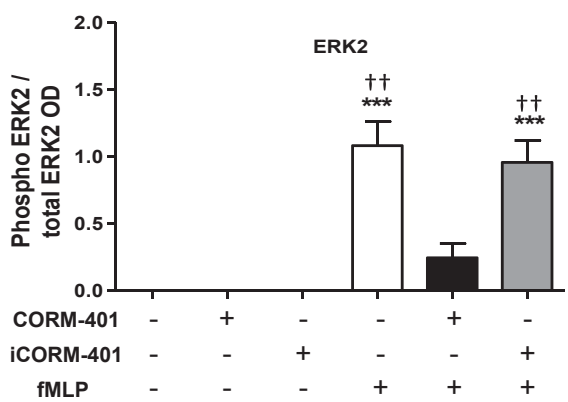

G

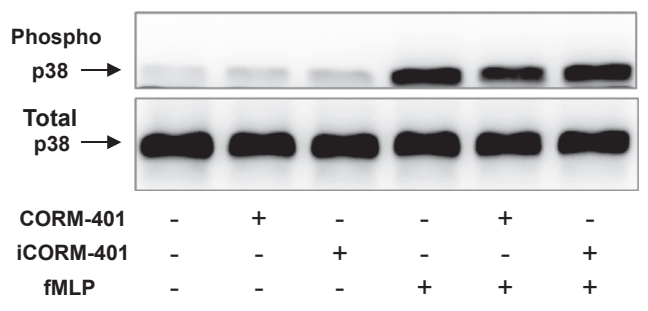

B

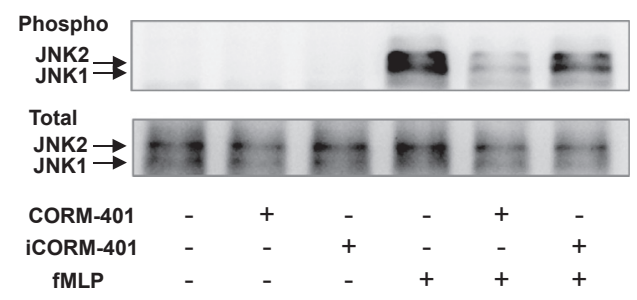

D

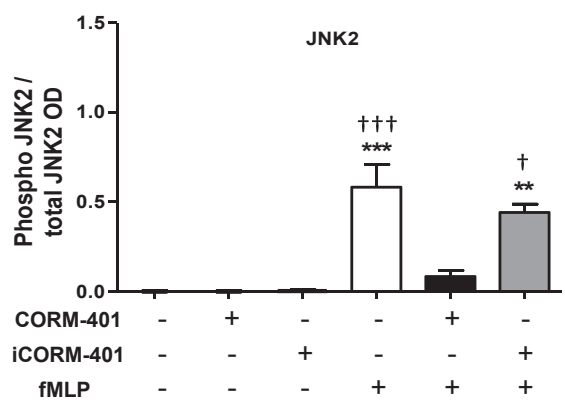

F

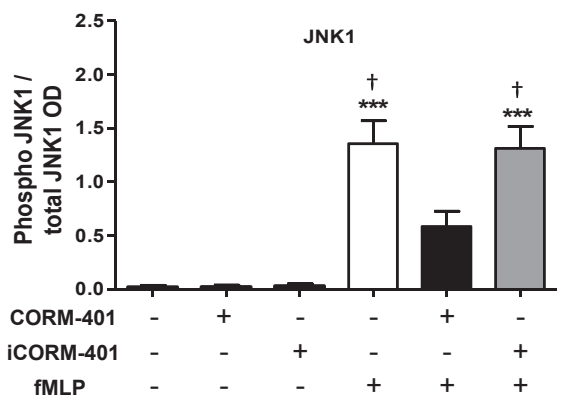

H

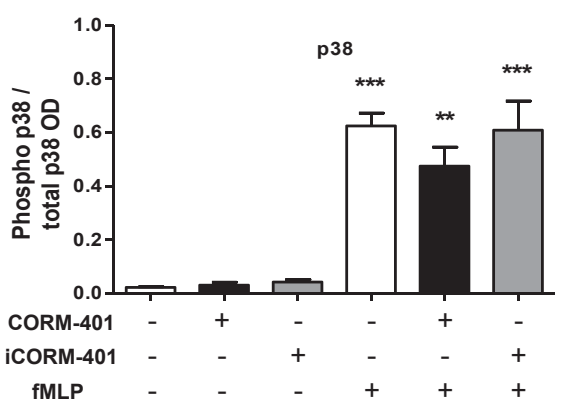

Figure 8 CORM-401 pretreatment suppresses activation of ERK1/2 and JNK1/2, but not p38 MAPK in fMLP-stimulated polymorphonuclear leukocytes (PMNs). PMNs were pretreated with $100 \mu \mathrm{mol} / \mathrm{L}$ CORM-401 or iCORM-401 for 30 minutes and stimulated with $0.05 \mu \mathrm{mol} / \mathrm{L}$ fMLP for 15 seconds. Subsequently, PMN samples were analyzed for activation (levels of phosphorylation) of ERK1/2 [ERK1 $\left(\mathrm{Thr}^{202} / \mathrm{Tyr}^{204}\right) /$ ERK2 $^{2}\left(\mathrm{Thr}^{185} / \mathrm{Tyr}^{187}\right)$ ] (A), JNK1/2 [JNK1/JNK2 (Thr ${ }^{183} /$ $\left.\left.\mathrm{Tyr}^{185}\right)\right]$ (B), and $\mathrm{p} 38\left(\mathrm{Thr}^{180} / \mathrm{Tyr}^{128}\right)$ (G) MAPKs by Western blot. Levels of ERK1/2, JNK1/2, and p38 phosphorylation were quantified by densitometry (OD) and standardized to the total levels of corresponding protein expression ( $\mathbf{C}$ and $\mathbf{E}, \mathbf{D}$ and $\mathbf{F}$, and $\mathbf{H}$, respectively). Representative blots from three independent experiments are shown. ${ }^{* *} P<0.01,{ }^{* *} P<0.001$ compared to unstimulated cells; ${ }^{\dagger} P<0.05,{ }^{\dagger \dagger} P<0.01$, and ${ }^{\dagger \dagger \dagger} P<0.001$ compared to CORM-401 + fMLP group. Phospho, phosphorylation.

PMN adhesion to LPS-stimulated endothelial cells under conditions of flow in vitro. Moreover, our data indicating CORM-401-dependent suppression of PMN migration velocity and directionality in response to fMLP-chemotactic gradient further support the role of PAK1/2 signaling in this phenomenon.

MAPKs (eg, JNK, ERK, and p38) are also known for their critical role in regulating cell migratory potential. ${ }^{53}$ 
Signaling pathways that control actin dynamics and cell migration (eg, Rac, FAK, and Src pathways) converge at JNK. ${ }^{53}$ ERK regulates focal adhesion turnover and cell migration, whereas p38 MAPK is known for its role in modulation of cell adhesion/actin dynamics during inflammation. ${ }^{53}$ Interestingly, both p38 and ERK interact with PAK to enable stimulus-induced reorganization of the actin cytoskeleton. fMLP induces phosphorylation of PAK1/2 and p38 MAPK, a step necessary for PAK interaction with the p38 MAPK and subsequent positive regulation of its activity. ${ }^{54}$ In addition, PAK1 plays a pivotal role in the regulation of cytoskeletal dynamics through ERK, as demonstrated by inhibitory effects on lamellipodia dynamics and cell locomotion by administration of ERK inhibitors. ${ }^{51}$

The results of the current study indicate that fMLP induces activation of all MAP kinases assessed (eg, ERK1/ 2, JNK1/2, and p38). Interestingly, pretreating PMNs with CORM-401 effectively suppresses phosphorylation of ERK1/2 and JNK1/2, but fails to interfere with fMLPinduced phosphorylation of $\mathrm{p} 38$ MAPK. The selective inhibition of ERK1/2 and JNK1/2 in fMLP-stimulated PMNs by CORM-401 supports our previous findings that CORM-3 selectively reduces JNK1/2 MAPK activation in an experimental model of endotoxemia (LPS stimulation of human cerebrovascular endothelial cells; hCMEC/D3) in vitro. ${ }^{55}$

The inability of CORM-401 to modulate fMLP-induced activation (phosphorylation) of p38 MAPK, on the other hand, is in conflict with the previous findings demonstrating CORM-401-dependent induction of p38 MAPK phosphorylation in naïve (unstimulated) endothelial cells ${ }^{56}$ and $\mathrm{CO}$ (gaseous form)-dependent amplification of p38 MAPK phosphorylation in LPS-stimulated macrophages. ${ }^{20}$ This discrepancy could be attributed to the different cell types used, duration of the cell treatment with CO/CORM-401, mode of CO/CORM-401 administration (ie, pretreatment versus cotreatment), and the experimental environment (ie, naïve versus inflammatory conditions) used.

Despite novel findings of the current study, future experiments are warranted to address discrepancies mentioned above and provide additional mechanistic and functional insights relevant to CORM-401-dependent modulation of PMN inflammatory activation.

Taken together, our findings indicate that CORM-401 is an effective and potent modulator of PMN migration and could be used as a potential therapeutic agent in mitigating an overwhelming recruitment of inflammatory cells (eg, $\mathrm{PMNs}$ ) to tissues/organs during severe inflammation.

\section{Acknowledgment}

We thank Prof. Christopher Chang (University of California, Berkeley, CA) for providing carbon monoxide probe-1.

\section{Supplemental Data}

Supplemental material for this article can be found at http://dx.doi.org/10.1016/j.ajpath.2016.12.025.

\section{References}

1. Singer M, Deutschman CS, Seymour CW, Shankar-Hari M, Annane D, Bauer M, Bellomo R, Bernard GR, Chiche JD, Coopersmith CM, Hotchkiss RS, Levy MM, Marshall JC, Martin GS, Opal SM, Rubenfeld GD, van der Poll T, Vincent JL, Angus DC: The third international consensus definitions for sepsis and septic shock (sepsis-3). JAMA 2016, 315:801-810

2. Martin CM, Priestap F, Fisher H, Fowler RA, Heyland DK Keenan SP, Longo CJ, Morrison T, Bentley D, Antman N: A prospective, observational registry of patients with severe sepsis: the Canadian Sepsis Treatment and Response Registry. Crit Care Med 2009, 37:81-88

3. Cepinskas G, Katada K, Bihari A, Potter RF: Carbon monoxide liberated from carbon monoxide-releasing molecule CORM-2 attenuates inflammation in the liver of septic mice. Am J Physiol Gastrointest Liver Physiol 2008, 294:G184-G191

4. Abraham E, Singer M: Mechanisms of sepsis-induced organ dysfunction. Crit Care Med 2007, 35:2408-2416

5. Jean-Baptiste E: Cellular mechanisms in sepsis. J Intensive Care Med 2007, 22:63-72

6. Riedemann NC, Guo RF, Ward PA: Novel strategies for the treatment of sepsis. Nat Med 2003, 9:517-524

7. Neviere RR, Cepinskas G, Madorin WS, Hoque N, Karmazyn M, Sibbald WJ, Kvietys PR: LPS pretreatment ameliorates peritonitisinduced myocardial inflammation and dysfunction: role of myocytes. Am J Physiol 1999, 277:H885-H892

8. Blom C, Deller BL, Fraser DD, Patterson EK, Martin CM, Young B, Liaw PC, Yazdan-Ashoori P, Ortiz A, Webb B, Kilmer G, Carter DE, Cepinskas G: Human severe sepsis cytokine mixture increases beta2-integrin-dependent polymorphonuclear leukocyte adhesion to cerebral microvascular endothelial cells in vitro. Crit Care 2015, 19: 149

9. Ley K, Laudanna C, Cybulsky MI, Nourshargh S: Getting to the site of inflammation: the leukocyte adhesion cascade updated. Nat Rev Immunol 2007, 7:678-689

10. Cepinskas G, Savickiene J, Ionescu CV, Kvietys PR: PMN transendothelial migration decreases nuclear NFkappaB in IL-1betaactivated endothelial cells: role of PECAM-1. J Cell Biol 2003, 161:641-651

11. Newman PJ, Newman DK: Signal transduction pathways mediated by PECAM-1: new roles for an old molecule in platelet and vascular cell biology. Arterioscler Thromb Vasc Biol 2003, 23: 953-964

12. Woodfin A, Voisin MB, Nourshargh S: PECAM-1: a multi-functional molecule in inflammation and vascular biology. Arterioscler Thromb Vasc Biol 2007, 27:2514-2523

13. Muller WA: Localized signals that regulate transendothelial migration. Curr Opin Immunol 2016, 38:24-29

14. Bodin S, Welch MD: Plasma membrane organization is essential for balancing competing pseudopod- and uropod-promoting signals during neutrophil polarization and migration. Mol Biol Cell 2005, 16: $5773-5783$

15. Baker MJ, Pan D, Welch HC: Small GTPases and their guanine-nucleotide exchange factors and GTPase-activating proteins in neutrophil recruitment. Curr Opin Hematol 2016, 23:44-54

16. Carstanjen D, Yamauchi A, Koornneef A, Zang H, Filippi MD, Harris C, Towe J, Atkinson S, Zheng Y, Dinauer MC, Williams DA: 
Rac2 regulates neutrophil chemotaxis, superoxide production, and myeloid colony formation through multiple distinct effector pathways. J Immunol 2005, 174:4613-4620

17. Reutershan J, Stockton R, Zarbock A, Sullivan GW, Chang D, Scott D, Schwartz MA, Ley K: Blocking p21-activated kinase reduces lipopolysaccharide-induced acute lung injury by preventing polymorphonuclear leukocyte infiltration. Am J Respir Crit Care Med 2007, 175:1027-1035

18. Paunel-Gorgulu A, Flohe S, Scholz M, Windolf J, Logters T: Increased serum soluble Fas after major trauma is associated with delayed neutrophil apoptosis and development of sepsis. Crit Care 2011, 15:R20

19. Gofton TE, Young GB: Sepsis-associated encephalopathy. Nat Rev Neurol 2012, 8:557-566

20. Otterbein LE, Bach FH, Alam J, Soares M, Tao Lu H, Wysk M, Davis RJ, Flavell RA, Choi AM: Carbon monoxide has antiinflammatory effects involving the mitogen-activated protein kinase pathway. Nat Med 2000, 6:422-428

21. Kim HP, Ryter SW, Choi AM: CO as a cellular signaling molecule. Annu Rev Pharmacol Toxicol 2006, 46:411-449

22. Hoetzel A, Dolinay T, Schmidt R, Choi AM, Ryter SW: Carbon monoxide in sepsis. Antioxid Redox Signal 2007, 9:2013-2026

23. Clark JE, Naughton P, Shurey S, Green CJ, Johnson TR, Mann BE, Foresti R, Motterlini R: Cardioprotective actions by a water-soluble carbon monoxide-releasing molecule. Circ Res 2003, 93:e2-e8

24. Motterlini R, Otterbein LE: The therapeutic potential of carbon monoxide. Nat Rev Drug Discov 2010, 9:728-743

25. Katada K, Bihari A, Mizuguchi S, Yoshida N, Yoshikawa T, Fraser DD, Potter RF, Cepinskas G: Carbon monoxide liberated from CO-releasing molecule (CORM-2) attenuates ischemia/reperfusion (I/R)-induced inflammation in the small intestine. Inflammation 2010, 33:92-100

26. Guo Y, Stein AB, Wu WJ, Tan W, Zhu X, Li QH, Dawn B, Motterlini R, Bolli R: Administration of a CO-releasing molecule at the time of reperfusion reduces infarct size in vivo. Am J Physiol Heart Circ Physiol 2004, 286:H1649-H1653

27. Caumartin Y, Stephen J, Deng JP, Lian D, Lan Z, Liu W, Garcia B, Jevnikar AM, Wang H, Cepinskas G, Luke PP: Carbon monoxide-releasing molecules protect against ischemia-reperfusion injury during kidney transplantation. Kidney Int 2011, 79: 1080-1089

28. Lawendy AR, Bihari A, Sanders DW, Potter RF, Cepinskas G: The severity of microvascular dysfunction due to compartment syndrome is diminished by the systemic application of CO-releasing molecule (CORM-3). J Orthop Trauma 2014, 28: e263-e268

29. Chung SW, Liu X, Macias AA, Baron RM, Perrella MA: Heme oxygenase-1-derived carbon monoxide enhances the host defense response to microbial sepsis in mice. J Clin Invest 2008, 118: 239-247

30. Mizuguchi S, Stephen J, Bihari R, Markovic N, Suehiro S, Capretta A, Potter RF, Cepinskas G: CORM-3-derived CO modulates polymorphonuclear leukocyte migration across the vascular endothelium by reducing levels of cell surface-bound elastase. Am J Physiol Heart Circ Physiol 2009, 297:H920H929

31. Zuckerbraun BS, Chin BY, Wegiel B, Billiar TR, Czsimadia E, Rao J, Shimoda L, Ifedigbo E, Kanno S, Otterbein LE: Carbon monoxide reverses established pulmonary hypertension. J Exp Med 2006, 203:2109-2119

32. Song R, Kubo M, Morse D, Zhou Z, Zhang X, Dauber JH, Fabisiak J, Alber SM, Watkins SC, Zuckerbraun BS, Otterbein LE, Ning W, Oury TD, Lee PJ, McCurry KR, Choi AM: Carbon monoxide induces cytoprotection in rat orthotopic lung transplantation via antiinflammatory and anti-apoptotic effects. Am J Pathol 2003, 163: $231-242$
33. Sener A, Tran KC, Deng JP, Garcia B, Lan Z, Liu W, Sun T, Arp J, Salna M, Acott P, Cepinskas G, Jevnikar AM, Luke PP: Carbon monoxide releasing molecules inhibit cell death resulting from renal transplantation related stress. J Urol 2013, 190: $772-778$

34. Urquhart P, Rosignoli G, Cooper D, Motterlini R, Perretti M: Carbon monoxide-releasing molecules modulate leukocyteendothelial interactions under flow. J Pharmacol Exp Ther 2007, 321:656-662

35. Crook SH, Mann BE, Meijer AJ, Adams H, Sawle P, Scapens D, Motterlini R: $[\mathrm{Mn}(\mathrm{CO}) 4\{\mathrm{~S} 2 \mathrm{CNM}(\mathrm{CH} 2 \mathrm{CO} 2 \mathrm{H})\}]$, a new watersoluble CO-releasing molecule. Dalton Trans 2011, 40: 4230-4235

36. Omatsu T, Cepinskas G, Clason C, Patterson E, Alharfi I, Summers K, Couraud PO, Romero I, Weksler B, Fraser D: CXCL1/CXCL8 (GROalpha/IL-8) in human diabetic ketoacidosis plasma facilitate leukocyte recruitment to cerebrovascular endothelium in vitro. Am J Physiol Endocrinol Metab 2014, 306: E1077-E1084

37. Shaw SK, Bamba PS, Perkins BN, Luscinskas FW: Real-time imaging of vascular endothelial-cadherin during leukocyte transmigration across endothelium. J Immunol 2001, 167: $2323-2330$

38. Kamakura S, Nomura M, Hayase J, Iwakiri Y, Nishikimi A, Takayanagi R, Fukui Y, Sumimoto H: The cell polarity protein mInsc regulates neutrophil chemotaxis via a noncanonical $G$ protein signaling pathway. Dev Cell 2013, 26:292-302

39. Michel BW, Lippert AR, Chang CJ: A reaction-based fluorescent probe for selective imaging of carbon monoxide in living cells using a palladium-mediated carbonylation. J Am Chem Soc 2012, 134: $15668-15671$

40. Martyn KD, Kim MJ, Quinn MT, Dinauer MC, Knaus UG: p21Activated kinase (Pak) regulates NADPH oxidase activation in human neutrophils. Blood 2005, 106:3962-3969

41. Sawle P, Foresti R, Mann BE, Johnson TR, Green CJ, Motterlini R: Carbon monoxide-releasing molecules (CO-RMs) attenuate the inflammatory response elicited by lipopolysaccharide in RAW264.7 murine macrophages. Br J Pharmacol 2005, 145: $800-810$

42. De Backer O, Elinck E, Blanckaert B, Leybaert L, Motterlini R, Lefebvre RA: Water-soluble CO-releasing molecules reduce the development of postoperative ileus via modulation of MAPK/HO1 signalling and reduction of oxidative stress. Gut 2009, 58: 347-356

43. Ryter SW, Otterbein LE: Carbon monoxide in biology and medicine. Bioessays 2004, 26:270-280

44. Ryter SW, Alam J, Choi AM: Heme oxygenase-1/carbon monoxide: from basic science to therapeutic applications. Physiol Rev 2006, 86: $583-650$

45. Boczkowski J, Poderoso JJ, Motterlini R: CO-metal interaction: vital signaling from a lethal gas. Trends Biochem Sci 2006, 31: 614-621

46. Foresti R, Bani-Hani MG, Motterlini R: Use of carbon monoxide as a therapeutic agent: promises and challenges. Intensive Care Med 2008, 34:649-658

47. Piantadosi CA: Carbon monoxide, reactive oxygen signaling, and oxidative stress. Free Radic Biol Med 2008, 45:562-569

48. Reddy RC, Standiford TJ: Effects of sepsis on neutrophil chemotaxis. Curr Opin Hematol 2010, 17:18-24

49. Kobayashi Y: The role of chemokines in neutrophil biology. Front Biosci 2008, 13:2400-2407

50. Taglieri DM, Ushio-Fukai M, Monasky MM: P21-activated kinase in inflammatory and cardiovascular disease. Cell Signal 2014, 26: 2060-2069

51. Smith SD, Jaffer ZM, Chernoff J, Ridley AJ: PAK1-mediated activation of ERK1/2 regulates lamellipodial dynamics. J Cell Sci 2008, 121:3729-3736 
52. Itakura A, Aslan JE, Kusanto BT, Phillips KG, Porter JE, Newton PK, Nan X, Insall RH, Chernoff J, McCarty OJ: p21Activated kinase (PAK) regulates cytoskeletal reorganization and directional migration in human neutrophils. PLoS One 2013, 8:e73063

53. Huang C, Jacobson K, Schaller MD: MAP kinases and cell migration. J Cell Sci 2004, 117:4619-4628

54. Aerbajinai W, Liu L, Chin K, Zhu J, Parent CA, Rodgers GP: Glia maturation factor-gamma mediates neutrophil chemotaxis. J Leukoc Biol 2011, 90:529-538
55. Serizawa F, Patterson E, Potter RF, Fraser DD, Cepinskas G: Pretreatment of human cerebrovascular endothelial cells with COreleasing molecule-3 (CORM-3) interferes with JNK/AP-1 signaling and suppresses LPS-induced pro-adhesive phenotype. Microcirculation 2015, 22:28-36

56. Fayad-Kobeissi S, Ratovonantenaina J, Dabire H, Wilson JL, Rodriguez AM, Berdeaux A, Dubois-Rande JL, Mann BE, Motterlini R, Foresti R: Vascular and angiogenic activities of CORM401, an oxidant-sensitive CO-releasing molecule. Biochem Pharmacol 2016, 102:64-77 